\title{
ARHEOLOGIJA IN GIS
}

\author{
Janez Dular, Božidar Slapšak, Zoran Stančič in Sneža Tecco-Hvala
}

\section{Pouzetek}

$V$ slovenski arheologiji je že od začetka osemdesetih let prisotna temeljna usmeritev $v$ arheologijo pokrajine. Ta smer temelji na domeni, da je človek $v$ preteklosti s suojim delovanjem pustil sledi $v$ celotni pokrajini in da je zato potrebno $v$ arheoloških raziskavah poselitve analizirati pokrajino in procese $v$ njej kot enoti bivanja. Medtem ko je arheološka stroka že vrsto let razvijala različne tehnike terenskega arheološkega pregleda, vključujoč sistematičen terenski pregled pokrajine, geofizikalne in geokemične meritve, fotointerpretacijo letalskih in satelitskih posnetkov, hkrati pa na interpretativnem nivoju prevzemala teoretske pristope iz geogrefije, pa smo šele $z$ razvojem GIS tehnologije dobili učinkovito orodje za ourednotenje tourstnih podatkov.

Osnouna izhodišča za aplikacijo GIS tehnologije so bila podana že pred leti $\mathrm{z}$ raziskovalnim projektom Geneze kulturne pokrajine na Oddelku za arheologijo ljubljanske Univerze. Pri sprejemanju GIS tehnologije je bil zlasti pomemben Projekt Huar, kjer smo $v$ sodelovanju s številnimi sorodnimi organizacijami doma in $v$ tujini opravili testno študijo. Raziskava je bila usmerjena predusem na možnost aplikacij GIS tehnologije $v$ širši arheološki raziskovalni sferi. Tu so zlasti pomembne raziskave o določanju ekonomskih meja preteklih družb, strategiji gospodarjenja in trgovanja, komunikacijah, upravljanju z naravnimi dobrinami in podobno.

Primerjava s situacijo $v$ drugih državah pa kaže, da je večinski delež aplikacij GIS tehnologije $v$ arheologiji prav na področju upravljanja s kulturno dediščino. Prav zato so $v$ toku kratke študije o poselitvi posameznih območij $v$ preteklosti, ki pa nam bodo dale vpogled tudi $v$ možnosti uporabe GIS tehnologije pri varovanju in upravljanju kulturne dediščine. Ključnega pomena je tu seveda kakovostna baza podatkov o arheoloških najdiščih Slovenije, ki sicer za sedaj le $v$ pisni obliki obstaja pri Inštitutu za arheologijo ZRC SAZU. Kompjuterizacija te baze bo $s$ primerno organizacijsko strukturo, uporabniškim vmesnikom in GIS nadgradnjo omogočala kakovostno integracijo arheoloških informacij $v$ slovenski GIS.

\section{Abstract}

UDC 902:91:681.3

\section{ARCHAEOLOGY AND GIS}

Concepts of spatial and landscape archaeology have been accepted within Slovene archaeology for a decade. These concepts are based on the assumption

Dr. Janez Dular in Sneža Tecco-Hvala, Inštitut za arheologijo ZRC SAZU, Gosposka 13, Ljubljana; dr. Božidar Slapšak in dr. Zoran Stančič, Oddelek za arheologijo, $\mathrm{FF}$, Univerza v Ljubljani. 
that man, by his diverse activities, made a tremendous impact on the landscape as a whole. Therefore in the research of archaeological settlement patterns, the whole landscape should be observed and analyzed. Diverse techniques of archaeological survey for data collection were developed and theoretical concepts for interpretation of those data were adapted from geography, but only by applying GIS technology were this concepts made accessible to all archaeologists.

Basic concepts for GIS applications were defined in the research project "The Genesis of the cultural landscape" at the Department of Archaeology of the University of Ljubljana. However, the Huar Project, as the first archaeological case study, played the crucial role in acceptance of GIS technology. The analyses were concentrated on the possibilities of GIS applications in archaeo logical analysis. The best results were achieved in definition of archaeological site territories, subsistence strategies, communi cations and trade analyses.

Few regional case studies were started this year because it is to be expected that soon the majority of the GIS archaeological applications will be in protection and management of cultural heritage. Simultaneously the Institute for Archaeology at the Slovene Academy of Sciences and Art has started with the computerization of the site and monuments database which will be integrated into the state GIS.

\section{PROSTORSKA ARHEOLOGIJA IN GIS}

Prostorski aspekt arheolških ostalin (materialnih ostalin preteklosti) je vedno imel svoje mesto pri konstituiranju podatka arheološke znanosti. Morda najznačilneje je konceptualiziran $v$ pojmu arheološke kulture kot prostorsko zamejene distribucije 'tipičnega' sklopa materialne kulture, pri čemer je implicirana podmena, da takšna distribucija $v$ danem časovnem segmentu predstavlja zaokroženo etnopolitično skupnost.

Eksplicitno prostorska arheologija, arheologija s programskim epitetom 'prostorska' torej, nastopi $z$ uveljavitvijo geografske paradigme $v$ arheologiji konec 60 let pod vplivom Nove geografije (Haggett, 1965; Chorley in Haggett, 1967; prim. Renfrew, 1969). Institucionalizira se skozi nove medstročne povezave, recimo na univerzi $v$ Cambridgeu, kjer nastopa kot paleoekonomija (programski teksti in aplikacije npr. $v$ Higgs in Vita Finzi, 1972; Higgs, 1975; pregled in metodološki principi prostorskih analiz v Hodder in Orton, 1976). Najjasneje jo je opredelil D. Clark (1977). Prostorsko problematiko je strukturiral na več ravneh: na eni strani lahko na makro ravni na primer opazujemo razporejenost in prepletanje prazgodovinskih kulturnih skupin v Srednji Evropi, na regionalni ravni nas lahko zanima distribucija arheoloških najdišč in na mikro ravni lahko opazujemo odnose med arheološkimi najdbami in strukturami znotraj posamičnega najdišča. Mnoge postavke prostorske arheologije so bile kmalu podvržene kritiki, spet pod vplivom novih smeri $v$ socialni geografiji, predvsem zaradi pretirane ekonomistične naravnanosti in nagnjenosti $h$ geografsko determinističnim razlagam (npr. Green in Haselgrove, 1978). 
Ena od radikalnejših izpeljav prostorske arheologije je arheologija pokrajine. Na eni strani obravnava pokrajino kot artefakt, na katerem se palimpsestno akumulirajo človekove intervencije, zato razvija postopke izčitavanja fizičnih struktur pokrajine kot socialnega prostora vsakokratnih skupnosti. Na drugi prelomi s konceptom arheološkega najdišča kot izolirane točke arheologovega zanimanja in obravnava pokrajino kot kontinuirano najdišče; tako razvija postopke sistematičnih kvantitativnih (površinskih in podpovršinskih) pregledov in diferencialno distribucijo artefaktov $\mathbf{v}$ prostoru interpretira kot podatek o preteklih dejavnostih oz. o funkcionalni in pomenski raznolikosti prostora (Flannery, 1976; Potter, 1979; Renfrew in Wagstaff, 1982; Keller in Rupp, 1983; Barker in Lloyd, 1991).

Načela prostorske arheologije so bila $\mathrm{v}$ slovenski arheologiji preizkušena $\mathrm{v}$ delu Slapšaka (1983), ki je na primeru Krasa apliciral različne modele iz socialne geografije in se spoprijel $\mathrm{z}$ vprašanji definiranja teritorijev in $\mathrm{s}$ sistemi poselitve pokrajine $\mathrm{v}$ preteklosti (prim. tudi Slapšak 1987). Postopki arheologije pokrajine so bili pri nas prvič uporabljeni v okviru projekta Hvar (prispevki v Chapman, Bintliff, Gaffney in Slapšak, 1988; gl. tudi Gaffney, Bintliff in Slapšak, 1991).

Prostorska arheologija je teoretične modele črpala predvsem iz geografije. Dober primer je poskus definiranja teritorijev naselbin $\mathrm{v}$ preteklosti $\mathrm{s}$ von Thunenovim (1876) modelom. Le-ta je znan in močno uporabljan $v$ geografiji že stoletje, $v$ arheološki stroki pa je prek angleške Nove geografije odkrit in prvič uporabljen šele $\mathrm{v}$ sedemdesetih letih (Vita-Finzi in Higgis 1970). Prav zaradi takšnih povezav $z$ geografijo je prostorska arheologija odprtih rok sprejela GIS. Seveda je res, da so določene arheološke šole bile bolj dovzetne za sprejemanje GIS tehnologije. Zlasti je izstopala ameriška arheološka šola, ki na eni strani že tradiciono podpira naravoslovno-matematične pristope, hkrati pa je prav tam pričela $\mathrm{v}$ šestdesetih letih takoimenovana kvantifikativna revolucija $z$ vsemi svojimi posledicami. Prve aplikacije GIS $\mathbf{v}$ arheologiji lahko zasledimo v zgodnjih osemdesetih letih (Kvamme, 1985), evropska arheologija pa je dokaj hitro sledila (Harris, 1986, Wansleeben, 1988). Zaradi že uveljavljenih pristopov prostorske arheologije v Sloveniji, so se prve aplika cije GIS pojavile dokaj hitro (Stančič in Gaffney, 1991).

Možnosti uporabe GIS $\mathrm{v}$ arheologiji nasploh so zelo široke, in to velja tako za raziskovalno kot za spomeniškovarstveno sfero. Čeprav je neizpodbitno dejstvo, da so prve aplikacije vedno za potrebe raziskav, pa je prav tako res, da napovedi kažejo, da bo v bližnji prihodnosti $90 \%$ arheoloških GIS aplikacij za potrebe spomeniškega varstva in upravljanja ter gospodarjenja s kulturno dediščino nasploh. Razloge za to je iskati predvsem v mnogo kompleksnejših organizacijskih problemih zlasti pri pripravi in vzdrževanju baze podatkov o arheoloških najdiščih. 


\section{STANJE RAZISKAV V SLOVENIJI}

Prvič smo GIS v slovenski arheologiji uporabili za potrebe raziskav mediteranske pokrajine $\mathrm{v}$ okviru mednarodnega Projekta Hvar. V okviru široko zasnovanega arheološkega raziskovalnega projekta, ki je vključeval strokovnjake različnih znanstvenih disciplin iz Hrvaške, Srbije, Anglije, Kanade in Slovenije, je zbrano gradivo o arheološki poselitvi otoka Hvara skozi tisočletja. Zbrani podatki so predstavljali osnovo za graditev računalniško podprte arheološke baze podatkov. Ker je bil eden od namenov študije ugotoviti odnose med poselitvijo otoka skozi arheološka obdobja in naravnim okoljem, smo zbrali podatke o reliefu, mikroklimi, pedologiji in geologiji za cel otok in jih organizirali $v$ GIS. V GIS smo nato integrirali bazo podatkov o arheoloških najdiščih. Ukvarjali smo se predvsem s problemi definiranja teritorijev oziroma vplivnih območij in meja arheoloških najdišč, analizirali smo ekonomske potenciale posameznih skupnosti ter izdelali prediktivni model poselitve in tras komunikacij (Stančič in Gaffney, 1991). Vse analize so opravljene pri Arkansas Archaeological Survey na Univerzi v Arkansasu, ZDA. Uporablili smo rastrski GIS imenovan GRASS, ki ga je za potrebe upravljanja in gospodarjenja $z$ zemljišči na svojih vadbenih področjih razvila ameriška vojska. GRASS je programski paket napisan v jeziku $C$ in dela pod operacijskim sistemom Unix. Prijazen programski paket, ki omogoča dostop do različnih modulov̀ na več načinov, od menijskega, prek interaktivnega za bolj izkušene uporabnike, do direktnih ukazov za eksperte, neprofitno distribuirajo številne ameriške vladne agencije in nekaj zasebnih podjetij $v$ Evropi in ZDA.

Po uspešnem zaključku študije mediteranske pokrajine in arheološke poselitve otoka Hvara, smo se odločili, da GIS tehnologijo širše uporabimo tudi na slovenskih tleh. Na Oddelku za arheologijo pri Univerzi v Ljubljani smo se zaradi že obstoječe opreme odločili da uporabimo GIS, ki bi omogočal delo na osebnem računalniku. Dobro možnost so predstavljali neprofitni GIS različnih geografskih oddelkov. Zaradi širokega spektra analitičnih možnosti, relativne enostavnosti uporabe in nizkih zahtev po strojni opremi, smo izbrali IDRISI, ki ga bolj ali manj uspešno uporabljamo že več kot dve leti. Ves ta čas je večina aplikacij usmerjenih v arheološke regionalne raziskave. Delamo na štirih regionalnih projektih, v različnih fiziografskih regijah in $z$ drugačnimi arheološkimi problemi (slika 1). Na področju Dolenjske analiziramo dinamiko sprememb poselitve v železni dobi, v Posavju, neposredni bližini Krškega, analiziramo poselitev v mlajši kameni dobi in zlasti poskušamo izdelati lokacijski model poselitve. Na Gorenjskem, s središčem na Bledu, analiziramo poselitev v zgodnjem srednjem veku. Kompleksnejše so analize poselitve Krasa, kjer poskušamo zajeti vsa arheološka obdobja. Nekateri od naštetih projektov so že v fazi finalizacije, pri nekaterih pa se še vedno ukvarjamo $z$ zagotavljanjem podatkovne baze.

V dosedanjih študijah so se zlasti izpostavili problemi zagotavljanja baze podatkov o naravnem okolju. Za potrebe regionalnih arheoloških analiz 
potrebujemo praviloma digitalni model reliefa, pedološke in geološke podatke ter vsaj grobe hidrološke podatke. Kljub relativno grobemu DMR-ju, ki je v Sloveniji na vso srečo dosegljiv, lahko ugotovimo, da je za regionalne analize zadovoljivo natančen. $\mathrm{Za}$ potrebe mikroregionalnih analiz omejenih območij je potrebno izdelati natančnejši DMR z natančnostjo $5 \mathrm{~m}$. Le taki podatki zagotavljajo natančne študije lokacij in tras komunikacij. Na regionalni ravni bi potrebam arheološke službe zadoščal že DMR $z$ natančnostjo $30 \mathrm{~m}$, saj bi za razliko od 100 - metrskega bistveno bolje podal tudi strukture reliefa, kot so naprimer grebeni, slemena, vrtače, jarki ipd. Na žalost pa imamo dosti več težav $z$ drugimi naravnimi podatki. Medtem ko so nekateri podatki o naravnem okolju, npr.pedologija, že na razpolago direktno v digitalni obliki, pa moramo za geološke in hidrološke podatke rešitev iskati $\mathrm{v}$ digitalizaciji. Geološke podatke si praviloma zagotavljamo $\mathrm{z}$ digitalizacijo geoloških kart v merilu 1:100 000, hidrologijo pa zajemamo iz topografskih kart 1:25 000. Tako smo naprimer $v$ dosedanjih raziskavah digitalizirali že desetino celotnega ozemlja Slovenije.

Ob uspešno izpeljanih raziskavah pa so se pojavile tudi določene težave. Tako kot tudi $v$ večini drugih disciplin, se uporabniki marsikdaj zadovoljijo že samo $z$ uporabo GIS kot orodja za digitalno kartiranje. Marsikdaj so analitične zmožnosti zanemarjene, predvsem zaradi pomanjkljivega poznavanja kvantifikativnih pristopov $v$ arheologiji nasploh. Ob tem se pojavlja tudi zahteva uporabnikov po izdelavi GIS modulov, ki bi bili bolj primerni za testiranje arheoloških hipotez različnih teoretičnih izhodišč. Neispodbitno je namreč, da je velika večina GIS programskih modulov narejena za potrebe splošnih geografskih raziskav. Prav tako je dejstvo, da te module praviloma uporabljajo vse stroke. Vendar pa se vsaj v arheologiji pojavlja težnja po razvijanju novih analitičnih orodij kot integralnega dela GIS, ki bi upoštevala tudi dejavnike, ki jih obstoječi moduli sicer zanemarjajo. Gre predvsem za upoštevanje, ob običajnh naravnih in socialnih, tudi idiosinkratičnih dejavnikov. Prav tako je res, da ob analizi vseh dejavnikov, ki jih ob arheoloških analizah želimo upoštevati, najtežje podamo izhodišča za subjektivne odločitve $\mathrm{v}$ preteklosti. Vsekakor velja, da objektivne dejavnike (tako naravne, npr. dostopnost vodnih virov, kakovost tal ipd., kot tudi socialne, npr. komunikacije, trgovanje) relativno lahko razumemo in tudi kvantificiramo, na drugi strani pa subjektivne (kult, verovanja...) bistveno težje. Le ti v analizah izstopajo in dajejo videz naključnega, vendar so bistvenega pomena za razumevanje preteklosti. Teh dejstev se v svojih raziskavah arheologi že ves čas zavedamo in prav zato se ne smemo čuditi izredno hitrim poskusom, de bi v analizah upoštevali tako ali drugače tudi te dejavnike. Prvi poskusi so omejeni predvsem na prilagajanje obstoječih modulov, kot je naprimer prilagajanje standardnega GIS modula, ki omogoča definiranje ploskev vidnih iz določene točke, v modul, ki definira percepcijo pokrajine in pomen določenih krajinskih struktur v preteklosti. Tem poskusom bodo verjetno sledile tudi resnejše in upajmo tudi uspešnejše raziskave, ki bodo omogočale $\mathrm{v}$ polni meri upoštevanje vseh pomembnih dejavnikov $\mathrm{v}$ tovrstnih prostorskih analizah. 
Zanimivo je, da GIS vpliva tudi na razvoj arheološke teorije. Na eni strani je že uveljavljenim pristopom, ki so počasi zastarali, dal nove dimenzije in jih posodobil. Dober primer za ta proces je modificiranje že omenjenega von Thunenovega modela, ki mu je GIS modul, ki teritorije definira glede na težavnost premikanja po terenu $v$ vseh smereh, podal popolnoma nove dimenzije. Čeprav je torej dejanski teoretični pristop popolnoma enak kot 100 let star geografski model, smo $z$ novo tehnologijo dobili mnogo boljše približke teritorijev (Stančič in Gaffney, 1991). Drugačen proces lahko opazujemo na primeru lokacijskih analiz, kjer vidimo, da tehnologija fizično omogoča na eni strani izvajanje pristopov, ki so sicer definirani že prej, vendar jih je bilo praktično težko izpeljati, hkrati pa postavljajo nove koncepte raziskav (Kvamme 1990).

\section{POTREBE IN PERSPEKTIVE}

Omenjene regionalne arheološke študije so osnova za nadaljnje delo za potrebe spomeniškega varstva. Neizpodbitno je dejstvo, da bo v bližnji prihodnosti večina aplakacij GIS $v$ arheologiji predvsem na področju spomeniškega varstva. Integracija arheoloških podatkov $\mathrm{v}$ geoinformacijski sistem na nivoju lokalnega ali pa regionalnega odločanja bo omogočala kakovostne odločitve pri posegih $\mathrm{v}$ kulturno dediščino. Prav zato smo mnenja, da je potrebno raziskovalne in operativne potenciale usmeriti $v$ računalniško podporo arheološke baze podatkov, ki jo vodi Inštitut za arheologijo ZRC SAZU.

Pri Inštitutu za arheologijo ZRC SAZU že vrsto let poteka permanentno zbiranje in urejanje podatkov o arheoloških najdiščih Slovenije. V prvi fazi, ki se je zaključila s publikacijo Arheološka najdišča Slovenije (1975), so se podatki zbirali predvsem po sekundarnih virih (literaturi, starih arhivih itd.) in dopolnjevali $z$ novejšimi odkritji. $V$ drugi fazi je sledilo in se še nadaljuje preverjanje in dopolnjevanje podatkov $s$ terenskimi pregledi in ugotavljanje natančnih lokacij. Izsledki se zbirajo $v$ obliki topografskih zapisnikov skupaj $\mathrm{z}$ obstoječo dokumentacijo (fotodokumentacijo, geodetskimi posnetki, skicami, izseki iz katastrskih kart itd.); rezultati ovrednotenja gradiva pa se objavljajo po topografskih področjih v obliki topografskih zvezkov (doslej so izšli trije - Bela krajina (Dular, 1985), Prekmurje (Šavel, 1991), Tržaška pokrajina (Flega in Župančič, 1991)). Prodiranje računalniške tehnologije na področje humanistike je vplivalo tudi na ta projekt in tako se tretja faza začenja $z$ oblikovanjem računalniške baze podatkov $o$ arheoloških najdiščih Slovenije; koncipirana je kot večuporabniška - dostopna bo preko računalniške mreže - in utemeljena $z$ dosedanjimi izkušnjami ter na zbranem gradivu. Trenutno je $v$ pripravi aplikacija in poskusni vnos.

V zasnovi je podatkovna baza zgrajena iz dveh sklopov; enega predstavlja opredelitev najdišča glede na prostor, vsebino, čas in varovanje, drugega pa stanje raziskav in zbrana dokumentacija $z$ literaturo, ki hkrati tudi 
pojasnjuje raven opredelitve. Strukturirana je večnivojsko - od splošnega k podrobnejšemu - odvisno pač od pridobljenih informacij. Tako so na prvem nivoju podatki zbrani $v$ sledeče rubrike:

1. prostorsko opredelitev, ki se opira na karte 1:5000 (TTN), kamor so vnešene doslej znane arheološke lokalitete in po kateri so povzete koordinate le-teh, preko katerih je možna povezava z GIS-om;

2. vsebinsko opredelitev, ki definira arheološko najdbo po enotnem geslovniku;

3. časovno opredelitev, ki vključuje najdbo $v$ standardizirano kronološko shemo;

4. spomeniškovarstveno opredelitev, ki se nanaša na režim zaščite najdišča;

5. splošni opis, ki zajema značilnosti najdišča, stanje ohranjenosti in komentar $\mathbf{k}$ dosedanjim ugotovitvam;

6. raziskanost navaja vrsto raziskav, ki so bile opravljene na nekem najdišču:

7. vir informacije navaja od kod so povzeti najdiščni podatki za računalniško zbirko;

8. literaturo, kjer je zbrana literatura o najdišču, ki vsebuje topografske podatke;

9. dokumentacijo, ki zajema informacije o fototeki, arhivskem gradivu, geodetskih posnetkih in risbah ter računalniško grafično dokumentacijo;

10. premični inventar, ki zajema podatke, kje in pod katero inventarno številko se nahajajo najdbe.

Gre torej za temeljno zbirko, ki bi po eni strani omogočala hiter dostop do ažurnih informacij o arheoloških najdiščih $v$ Sloveniji in enostavno iskanje željenih kombinacij, po drugi strani pa nadgradnjo le-teh v različnih smereh s pomočjo drugih podatkovnih zbirk, ki jo omogoča GIS tehnologija, kjer bi arheološka baza podatkov predstavljala le en informacijski sloj npr. pri proučevanju vpliva okolja na poselitveno strukturo $v$ arheoloških dobah, ugotavljanje komunikacij, ekonomike itd., povratno pa bi bila osnovna informacija $\mathrm{v}$ spomeniškovarstvenih odločitvah.

\section{ZAKLJUČEK}

GIS je v arheologiji že uveljavljeno analitično orodje predvsem v regionalnih raziskavah. Medtem ko so ga raziskovalne strukture odprtih rok sprejele, pa bo delo na področju varovanja naravne in kulturne dediščine težavnejše. Spoprijeti se bo treba zlasti $z$ organizacijskimi problemi ter vzdrževanjem baze podatkov o arheoloških najdiščih Slovenije. $Z$ di se, da se bodo rastrski sistemi povečini uporabljali na raziskovalnih inštitucijah, medtem ko bodo spomeniškovarstvene aplikacije bolj primerne za lokacijske informacijske sisteme vektorske osnove. Arheološko stroko zato zlasti zanimajo možnosti izmenjave obstoječih podatkov bodisi na regionalni ravni, ali pa širše, $z$ drugimi inštitucijami. Zato tudi bazo podatkov o arheoloških najdiščih Slovenije vidi kot integralni del celovite baze podatkov o 
okolju, saj se zaveda, da bo le tako v celoti izkoriščena. Arheološka izkušnja je pri tem lahko vodilo za koncipiranje dela na področju kulturne dediščine nasploh.

\section{LITERATURA IN VIRI}

Arheološka najdišča Slovenije 1975, Slovenska akademija znanosti in umet-. nosti, Razred za zgodovinske vede.

Barker B. in Lloyd J. eds. 1991: Roman landscapes, Archaeological survey in the Mediterranean region, Archaeological Monographs of the British School at Rome 2.

Bavec U. 1988: An interim report of survey work carried out at Sveti Jakob, a multi-period hilltop settlement above Dovsko (Senovo), Slovenia, v: Chapman, Bintliff, Gaffney in Slapšak 1988, 225-239.

Bavec U. 1989: Prispevek $\mathrm{k}$ metodam arheološkega terenskega pregleda in slovenska izkušnja, Arheo 9, 34-41.

Budja M. 1989: Arheološki zapisi na površju - palimpsesti preteklih stanj, Poročilo o raziskovanju paleolita, neolita in eneolita v Sloveniji 17, 83-102.

Chapman J.C., Bintliff J., Gaffney V. in Slapšak B. eds. 1988: Recent developements in Yugoslav archaeology, British Archaeolog ical Reports, International Series 431, Oxford.

Chorley R.J. in Haggett P. eds. 1967: Models in Geography, Methu en, London.

Clark D.L. 1977: Spatial information in archaeology, v D.L.Clark ed., Spatial archaeology, Academic press, 1-32.

Dular J. 1985: Arheološka topografija Slovenije, Topografsko področje XI (Bela krajina), Slovenska akademija znanosti in umetnosti, Razred za zgodovinske vede.

Flannery K.V. ed. 1976: The early Mesoamerican village, Academic Press, New York.

Flega J. in Župančič M. 1991: Arheološka topografija občine Dolina (Tržaška pokjrajina, Italija), Narodna in študijska knjižnica Trst, Odsek za zgodovino, in Znanstveno raziskovalni center Slovenske akademije znanosti in umetnosti, Inštitut za arheologijo.

Gaffney V.L., Bintliff J. in Slapšak B. 1991: Site formation processes and the Hvar survey project, Yugoslavia, v: Schofield A.J. ed., Interpreting artefact scatters: contributions to ploughzone archaeology, Oxbow Monograph 4, Oxford.

Green D.R. in Haselgrove C.C. 1978: Some problems of cross- disciplinary communication as viewed from archaeology and geography, v: Green D.R., Haselgrove C.C. in Spriggs M. eds, Social organisation and settlement, British Archaeological Reports, International Series 47, Oxford, VII-XXXVI.

Grosman D. 1989: Tehnike terenskega pregleda, Arheo 9, 59-63.

Haggett P. 1965: Locational analysis in human geography, E.Arnold, London. 
Harris T.M. 1986: Geographic information system design for archaeological site information retrival, v S.Laflin ed., Computer applications in archaeology 1986, University of Birmingham, 148- 161.

Higgs E.S. ed. 1975: Palaeoeconomy, Cambridge Univesity Press.

Higgs E.S. in Vita Finzi C. 1972, Prehistoric economies, A territorial approach, v: Higgs E.S. ed., Papers in economic prehistory, Cambridge Univesity Press.

Hodder I-R. in Orton C. 1976: Spatial analysis in archaeology, Cambridge University Press.

Keller D.R. in Rupp D.W. eds. 1983: Archaeological Survey in the Mediterranean area, British Archaeological Reports, International Series 155, Oxford.

Kvamme K.L. 1985: Determining empirical relationships between the natural environment and prehistoric site locations: a hunter- gatherer example, v C.Carr ed., For concordance in archaeological analyses, Westport publishers; 208-238.

Kvamme K.L. 1990: The fundamental principles and practice of pre dictive archaeological modeling, $\mathrm{v}$ A.Voorrips ed., Mathematics and information science in archaeology: a flexible framework, Studies in modern archaeology, vol.3, Holos verlag, 257-295.

Potter, T.W. 1979: The changing landscape of Southern Etruria, Elek, London.

Renfrew C. 1969: recenzija: Haggett 1965, Chorley in Haggett 1967, Antiquity $43,74-75$.

Renfrew C. in Wagstaff eds. 1982: An island polity: the archaeology of exploitation in Melos, Cambridge University Press.

Slapšak B. 1983: Možnosti študija poselitve v arheologiji, doktorska disertacija, Univerza v Ljubljani, Filozofskla fakulteta.

Slapšak B. 1987: Defining the economic space of a typical Iron Age hillfort: Rodik (Yugoslavia), a case study, v: Bintliff J.

Davidson D.A. in Grant E.G., Conceptual issues in environmental archaeology, Edinburgh University Press, 95-107.

Stančič Z. in Gaffney V. 1991: Napovedovanje preteklosti - uporaba GIS v arheološki študiji otoka Hvara, Znanstveni inštitut Filozofske fakultete.

Šavel I. 1991: Arheološka topografija Slovenije, Topografsko področje XX (Prekmurje), Slovenska akademija znanosti in umetnosti, Razred za zgodovinske vede.

Thunen von J.H. 1876: The isolated state, Oxford University Press 1966.

Vita-Finzi C. in Higgis E.M. 1970: The prehistoric economy of the Mt.Carmel area, Proceedings of the Prehistoric society $36,1-37$.

Wansleeben M. 1988: Geographic information systems in archaeolog ical research, v S.P.Q.Rahtz ed., Computer and quantitative methods in archaeology 1988, British Archaeological Reports International Series 446, vol.2, 435-451. 
Janez Dular et al.

222

Arheologija ...

Slika 1: Območja prostorskih analiz z GIS.

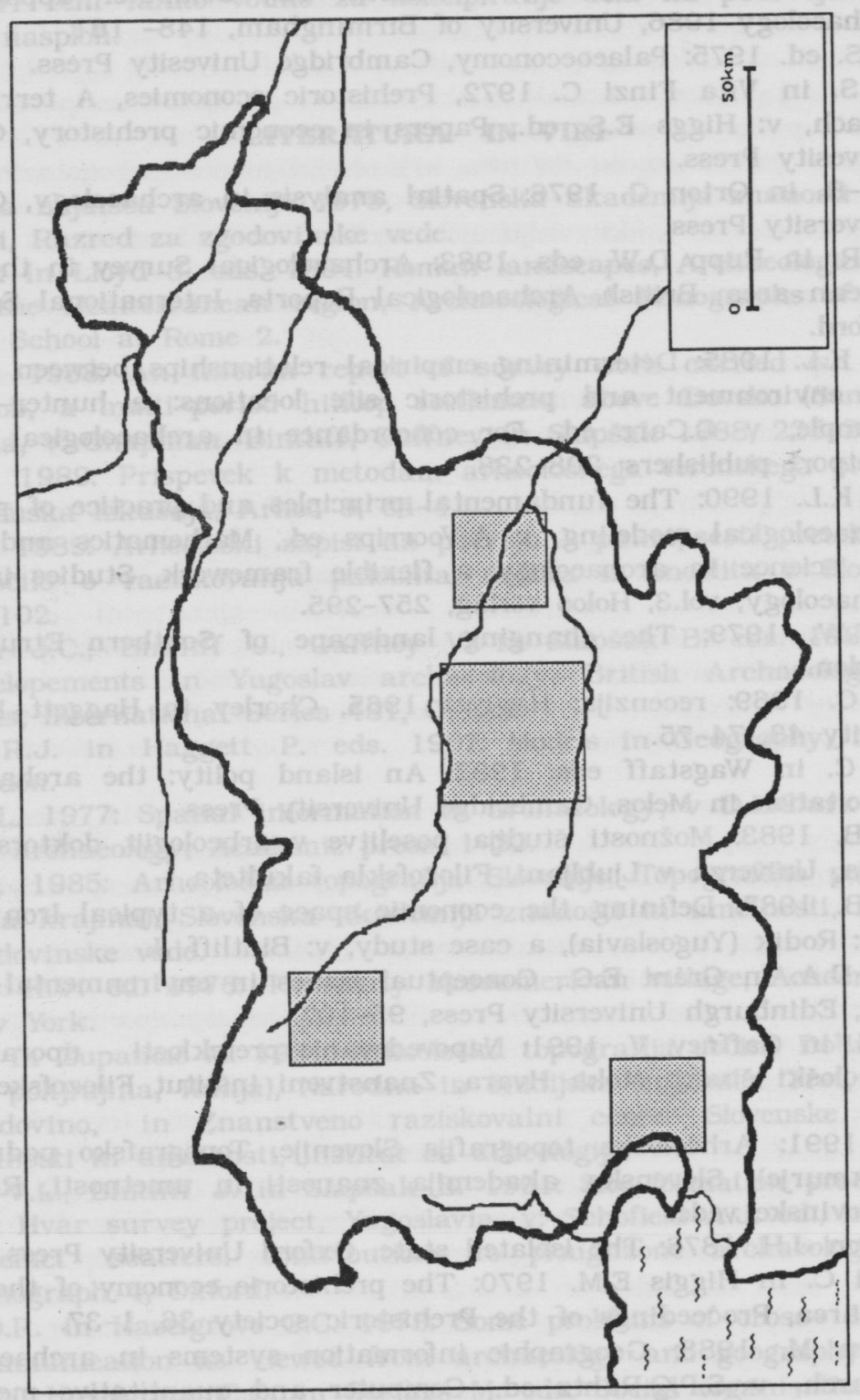

